\title{
Innovation Ecosystem Emergence Barriers: Institutional Perspective
}

\author{
Argyro Almpanopoulou \\ Lappeenranta University of \\ Technology \\ argyro.almpanopoulou@lut.fi
}

\author{
Paavo Ritala \\ Lappeenranta University of \\ Technology \\ paavo.ritala@lut.fi
}

\author{
Kirsimarja Blomqvist \\ Lappeenranta University of \\ Technology \\ kirsimarja.blomqvist@lut.fi
}

\begin{abstract}
Innovation ecosystems are built around new technologies, ideas, and innovations and their supporting actors and structures. However, the emergence of ecosystems is constrained by a host of institutional, system-level barriers in the existing organizational field that inhibit the legitimacy, resourcing, and growth of new initiatives. Through an empirical study in the Finnish energy sector, we find a strong and interdependent set of regulative, normative, and cultural-cognitive barriers that restrict the emergence of innovation ecosystems with new technologies. In particular, we identify a set of barriers and related field-sustaining mechanisms. The findings offer important implications for the theory and practice of innovation ecosystem emergence and related system-level barriers.
\end{abstract}

\section{Introduction}

Innovation ecosystems enable actors, technologies, and institutions to come together to create and commercialize new products and services (e.g., [33], [31], [12]). As open social systems (e.g., [7]), they enable dynamic inflows and outflows of resources and provide a shared institutional logic for the emergence of different types of innovation [46]. However, creating new ecosystems is not easy. As new innovation ecosystems emerge $^{1}$, they often disrupt existing social, technological, and organizational fields and regimes (e.g., [20], [5]). Thus, as new ecosystems pursue new trajectories and paths, effectively replacing some old ones [3], they often face both deliberate and 'passive' resistance from different types of actors and institutions.

\footnotetext{
${ }^{1}$ Emergence describes how complex systems arise out of a set of interactions; however, the connection between the actions of individual actors and the systemic outcome is uncertain [40]. In addition to new ecosystem emergence, we also consider the transformation or renewal of a mature ecosystem to be a form of emergence, since it involves profound restructuring and other organization-level changes [26] that can lead to unpredictable and even surprising outcomes at the ecosystem level.
}

The literature on innovation and strategy has provided considerable evidence of entry barriers, a topic that has been discussed since the classic Porterian analysis of industry forces [30]. However, the entry barrier literature has typically focused on the barriers for single actors, rather than on the dynamic counterforces that prevent the emergence of whole ecosystems. More recently, scholars have begun to examine how the entry of new technologies and related actors and institutions occurs in various system-level settings (e.g., [10], [5], [13], [24]). Further, the literature on organizational and institutional fields has examined pathways to field change, including the entrance of new technologies and actors [49].

However, a comprehensive understanding of barriers and constraining mechanisms is largely absent in the innovation ecosystem literature, which has focused mostly on how existing businesses build and manage their ecosystems (e.g., [33], [47], [31]). This literature recognizes that the rise of new ecosystems, sudden changes in environmental conditions (e.g., new regulations or customer buying behaviors), and changes in macroeconomic conditions can threaten mature ecosystems [26]. In other words, the research on innovation ecosystems sees the wider environment as a trigger for the renewal (or death) of these ecosystems. Yet, this literature has paid less attention to how the broader environment and accompanying institutions might create barriers to innovation ecosystem emergence and the pre-formation phases of innovation ecosystems. In these phases, actors are still looking for opportunities to develop new innovations for the field, and ecosystem emergence typically requires collective action, a jointly adopted vision, and actors taking a lead on various issues [6, 29]. By contrast, the absence of these conditions acts as a barrier to ecosystem emergence. The outcome of this phase is unpredictable; however, actors' choices and actions are increasingly influenced by and embedded in institutions, and the rules and culture that serve as institutional building blocks [35]. Existing innovation ecosystem research has not provided overarching evidence of the barriers that inhibit the processes (e.g., collective action, initiative taking) that lead to ecosystem emergence. 
To address these research gaps and better understand the systemic nature of ecosystem emergence barriers, we follow [20], who suggest that socio-technical transitions can be examined through analyses of organizational and institutional fields [14] [49]. The institutional literature has long recognized that the emergence of new technologies and innovations involves complex institutional dynamics that require not only technological changes, but also a focus on user practices, regulation, infrastructures, and symbolic and cultural issues (e.g., [18], [19], [25]). These, in turn, might create a strong level of institutionalization, which is sustained through an interplay with both issue fields, in which powerful actors push back against radical developments, and market exchange fields, in which transactions are dominated by incumbent actors (cf. [49]). Institutional lenses have recently been applied to the literature on innovation ecosystems. [43] suggest that an institutional approach-and, particularly, an organizational fields approach — is useful for studying the dynamics and boundaries of ecosystems. Furthermore, [6] suggest that creating new ecosystems requires the establishment of institutional legitimacy among relevant stakeholders.

In the current paper, institutional lenses are adopted to examine the diversity and strength of the institutions new ecosystem initiatives face and to understand the heretofore understudied dynamic counterforces of innovation ecosystem emergence. Based on this foundation, we propose the following research question: What are the barriers that inhibit ecosystem emergence, and how are these barriers sustained? To answer our research question, we conduct a qualitative inquiry with rich empirical evidence from the organizational field of the Finnish energy sector. Specifically, to examine ecosystem emergence, we select the "digitalization" of the energy sector as our empirical context. Utilizing an empirical study, we identify four ecosystem emergence barriers and related field-sustaining mechanisms. We find that the Finnish energy sector includes a strong and interdependent set of regulative, normative, and cultural-cognitive barriers that restrict ecosystem emergence. In particular, we build a model that explains how regulation and policymaking ambiguity, incumbent actor inertia, and cognitive constraints for opportunity recognition mutually reinforce one another. Our model also explains how the institutional complexity of the energy field functions as an overarching barrier. The results contribute to the understanding of the preemergence phase of ecosystems and related institutional barriers.

The paper proceeds as follows. First, we discuss the conceptual background of innovation ecosystems and their emergence, followed by a broader discussion of institutional barriers. Second, we describe our methodological choices and then draw conclusions regarding ecosystem emergence barriers. Finally, we discuss the implications for theory and practice and suggest future research directions.

\section{Conceptual background}

\subsection{Innovation ecosystem emergence}

The concept of innovation ecosystems is widely debated (see, e.g., [34], [27], [1], [44]); however, consensus is forming around some key features. In particular, we follow the recent conceptualization of [32, p. 41], who define innovation ecosystems as "systems that focus on innovation activities (goal/purpose), involve the logic of actor interdependence within a particular context (spatial dimension) and address the inherent co-evolution of actors (temporal dimension)." Innovation ecosystem actors typically include private firms that develop new technologies, universities and research institutions, and complementary firms that provide necessary technological components, inputs, and market access [3].

The existing research on innovation ecosystems has examined how such ecosystems are purposefully built by leading firms [33], [2], [31], as well as how they emerge around broader socio-technical regimes and industry-crossing economic developments [13], [34]. In this study, we focus particularly on the latter context: a broader system-level interdependence of actors that engage in innovation activities. Ecosystems are built around interdependencies of actors, technologies, and institutions [1]; therefore, the emergence of an ecosystem is a complex feat in itself. However, analyzing actors' pursuits with respect to new ecosystem creation is not sufficient; we must also understand the existing and incumbent actors, technologies, and institutions that provide the fieldlevel context within which (potential) emergence occurs.

While ecosystems span several industry boundaries [47], [26], their emergence shares some features with industry emergence. In examining industry emergence, [24] differentiate among three phases. In the first stage, a disruption to the existing industrial order triggers a second, co-evolutionary stage, which includes four sub-processes related to developments in technology, markets, activity networks, and industry identity. The convergence of these sub-processes leads to the third, growth stage and the birth of a new industry. Similarly, during their emergence phase, innovation ecosystems 
first begin to disrupt existing actors, technologies, and institutions (e.g., [3]), while simultaneously confronting resistance from incumbents. Second, as an ecosystem develops, a co-evolution of new and existing actors, technologies, and institutions occurs (see [3]). Finally, innovation ecosystems enable the commercialization of ideas, inventions, and technologies, creating new businesses, industries, and ecosystems and, thus, integrating the systems' explorative features through exploitation [45].

In the current study, we are particularly interested in the early pre-emergence phase, during which actors pushing for new initiatives are still struggling to find ways to foster ecosystem creation. To understand this phase, we turn our attention to the institutional barriers formed at the level of organizational fields (i.e., the context in which ecosystem emergence occurs).

\subsection{Institutional barriers in organizational fields}

In general, institutions act as constraints and facilitators for innovation and technological development [13], [25]. Institutions are broadly seen to affect all organizational actions and interactions within a particular field (e.g., the energy sector) and to include regulative, normative, and cultural-cognitive aspects (see, e.g., [19], [25]).

In the current study, we view the field level as the context for analyzing institutional barriers to ecosystem emergence. Organizational fields are defined as "those organizations that, in the aggregate, constitute a recognized area of institutional life: key suppliers, resource and product consumers, regulatory agencies, and other organizations that produce similar services or products" [14 p. 148]. The field level has been the key frame for analyses in institutional theory, as it explains the relevant contexts for institutional phenomena [49]. Recently, institutional theory has also begun to look at institutional fields more broadly, including fields formed around opinions, politics, norms, debates, and organizational arrangements (cf. [49]). For ecosystem emergence, examining the full variety of institutional phenomena at the field level is particularly important, given the co-evolving and interdependent nature of ecosystems and their business environments (e.g., [1]).

When analyzing institutional barriers for innovation ecosystem emergence, examining legitimacy is particularly important. As suggested by [6], new ecosystem creation involves building legitimacy across various stakeholders, involving regulative issues, technological aspects, and cognitive and symbolic meanings. This broadly follows the tradition of institutional theory, in which legitimacy is divided into regulative, normative, and cognitive (see [36], [25], [41]). Regulative legitimacy refers to the degree to which an organization (or ecosystem) aligns with existing processes for rule-setting, monitoring, and sanctioning. Normative legitimacy is defined as "a degree of congruence or fit between the actions, characteristics, and form of the organization and the beliefs and cultural values of the broader social environment within which it exists" [41, p. 454]. Finally, cognitive legitimacy refers to a high degree of alignment between an organization's "taken-forgranted" expectations and its environment (see, e.g., [4]).

For ecosystem emergence, all three types of legitimacy are required; in other words, all three types of legitimacy might appear as constraining forces in the organizational field. Therefore, analyzing the institutional forces and related legitimacy is important for understanding not only the context of ecosystem emergence, but also the barriers that might prevent emergence from happening in the first place.

\section{Methods}

The following sections discuss our methodological choices. After elaborating the research strategy and how it evolved, we describe the empirical setting of the study. Finally, we discuss our approach to the data collection and analysis.

\subsection{Research design and empirical setting}

This study originated from a broader research project on the emergence of innovation ecosystems that initially did not focus on institutional barriers. Rather, this focus emerged during the data collection and analysis, and we interpreted it as a prominent feature of the empirical phenomenon and, thus, a promising theme for theorizing. Therefore, we progressively focused [28], [38] (see Figure 1) our study on the emerging issue of ecosystem emergence barriers and formulated our final research question as follows: What are the barriers that inhibit innovation ecosystem emergence, and how are these barriers sustained? We then turned to institutional theory (e.g., [14], [36]), which we utilized to sensitize our theorizing. Specifically, we focused our study on the level of the organizational field [14], [48], [49], initially choosing to examine the regulative, normative, and culturalcognitive institutional elements [36]. To answer our research questions, we relied on an in-depth qualitative inquiry, which we consider to be consistent with our 
research goals and the exploratory nature of the study (see [15]).

The empirical context of this study focuses on the energy sector in Finland, which comprises a variety of actors ranging from major players to several middlesized firms and an increasing number of innovative start-ups. The energy sector is an interesting empirical context because it is one of the industries least disrupted by digitalization both in Finland and globally (compared, for instance, to the media and telecommunications sectors). Digitalization and related business models represent a new socio-technical regime [20] in the energy sector, which is currently emerging and will eventually replace some older business models and practices. As a highly regulated and capital-intensive sector, we believe that the energy sector is well suited to the study of the institutional barriers to ecosystem emergence. For the purposes of the current study, the energy sector represents the level of analysis of an organizational field in which we examine these barriers and related field-sustaining processes. Incumbent and established actors in the energy sector are interdependent because they must codevelop the capabilities to respond to this new era. Therefore, we perceive the energy sector as a feasible empirical context for studying the barriers to ecosystem emergence.

\subsection{Data collection}

Our data collection process comprised semistructured interviews. We interviewed 26 key informants representing different organizations to ensure a variety of viewpoints and, thus, to increase the validity of the findings [23]. We first utilized archival material to identify the key respondents to interview and then used a snowballing technique to identify further respondents. We collected our data in two phases (see Figure 1). First, we interviewed eight experts in the energy sector to gain a general understanding of the specific field and its current state in terms of digitalization. During this phase, we observed that there were certain barriers that obstructed the emergence of new ecosystems. This led us to turn to institutional theory. Accordingly, we conceptualized the energy sector as an organizational field and formulated our final research question. In the second phase, we updated our interview guide to include questions about the roles of institutions and regulations, as well as the roles and activities of various actors. We then conducted 18 additional interviews with key informants representing different actors within the organizational field. The interviewees represented a wide variety of experts, including six leading energy sector academics, two research institute representatives, five policy makers, ten company representatives, two industry association representatives, and one representative of a non-governmental organization.

\subsection{Data analysis}

Our analytical procedure was guided by the principles of grounded theory (GT). The GT approach provides tools with great potential for analyzing processes [8], making it a relevant and well-aligned analytical strategy for explaining the dynamic phenomenon under examination. In the first phase of the data analysis, the first author independently started the analysis with initial coding utilizing NVivo. This phase involved coding sentences or segments of the data depending on their richness. We tried to remain open to what our material suggested and used in-vivo coding when applicable. The initial codes varied in length from a couple of words to full sentences. In the second phase of our analysis, the second and third authors were actively involved through discussions and multiple iterations of the initial codes. At the beginning of this phase, the second and third authors examined the initial codes separately and provided comments, questioning the analytical decisions and helping to raise the level of abstraction. We then selected the codes that were the most significant, appeared most frequently, or made the most analytic sense and started to sort and organize them into focused codes (see [8]). Our approach to the data analysis followed an iterative cycle of inductive patterns involving reflection back and forth with theory (cf. [22]) that made it possible to draw broad patterns from the data. Additionally, the different analytical roles allowed for researcher

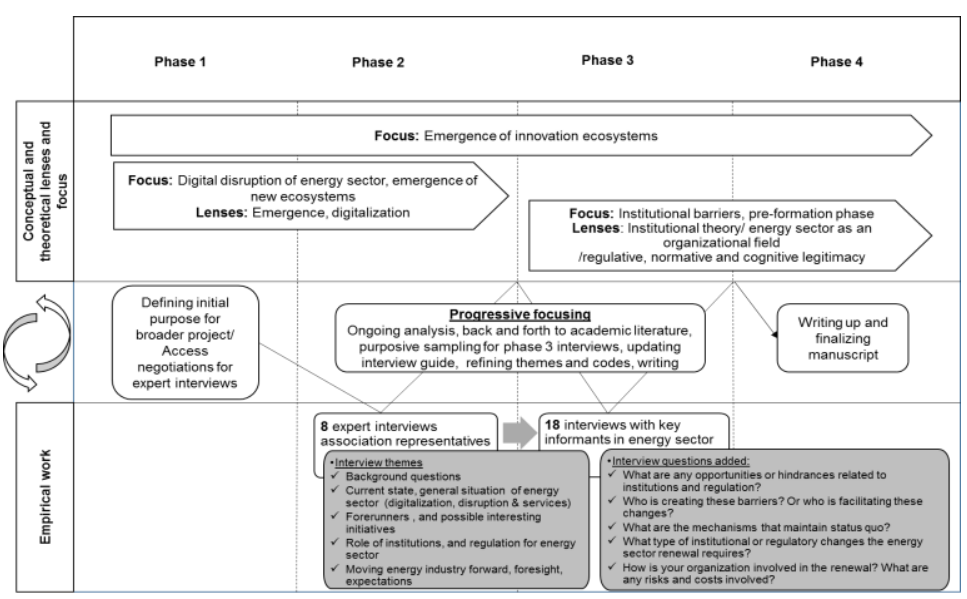

Figure 1. Progressive focusing of our study adapted by [38] triangulation, yielding a more comprehensive and 
heterogeneous set of perspectives, which we synthesized during the analysis process. The findings presented in the following section are an outcome of this analysis process.

\section{Findings}

Our empirical analysis revealed four main barriers to innovation ecosystem emergence: incumbent actor inertia, regulation and policymaking ambiguities, cognitive constraints for opportunity recognition, and institutional complexity. In the following sections, we elaborate on each of the four barriers, the mechanisms that sustain them, and how they mutually reinforce each other. Figure 2 depicts our overall findings regarding these institutional counterforces to innovation ecosystem emergence.

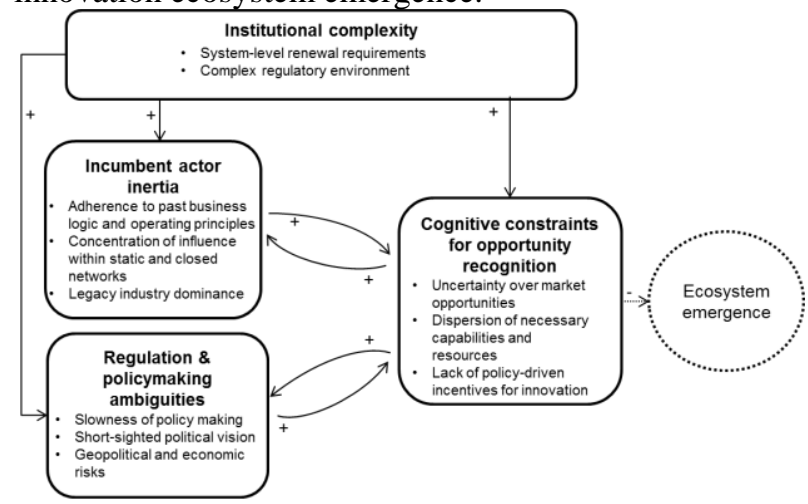

Figure 2. Institutional counterforces to innovation ecosystem emergence.

\subsection{Incumbent actor inertia}

Though we identified some innovative and flexible players pushing for energy sector digitalization, we found incumbent actors' inertia to be a prominent barrier to new ecosystem emergence and the evolution of existing ecosystems. Overall, our informants described the organizational field as static and conservative. Incumbent actors were perceived as hesitant to drive change; their adherence to the past business logic and operating principles sustained the existing field instead of allowing for renewal. The following quotation vividly captures this issue: "They want large power plants, and historically, they've learned that this is the right thing to do, and maybe it has been the right thing to do, and it's okay, but now times are changing. But if you are within this group and within this bubble, it's very difficult to completely revise your thinking and think of the roadmap that: How do we go from this point A to the new immaterial digital world?" This trend includes energy companies, which fear cannibalizing existing investments/business and are reluctant to test new business models. Related to this issue is the lengthy life cycle of investments in the energy sector. For example, power plant investments have a life cycle of 35 to 40 years, and companies expect to keep the plant running for that time. The long economic lifetimes of these kinds of investment create a kind of natural inertia among incumbent actors.

In addition, the concentration of influence within static and closed networks sustains the bargaining power and legitimacy of these actors. The strong ingroup socialization within a relatively small and homogeneous group of influential actors and individuals leads to the formation of "bubbles" of consensus thinking, which result in high normative institutional barriers. In fact, the small number of influential individuals and their tight interconnections when making key decisions concerning, for example, energy policy and other decisions that affect the field, leads to a lack of outsider perspectives and can result in new digital business model initiatives being left on the sidelines: "Energy policy will then, basically, be done behind closed doors, and [those] who are inside the closed doors, they will determine very much the contents of the energy policy." These large incumbents have developed a situation similar to a monopoly, creating a culture and mindset that lacks innovation and customer focus.

Legacy industry dominance relates to the strong presence and influence of current incumbent industries, such as the forestry (or "bio-economy") industry and the nuclear industry, among other dominant sectors. Our respondents viewed the increased availability of bio-based energy in Finland, as well as the access to key resources and financial support that historically lies within these sectors, as potentially harmful for the transformation of the energy sector. The power of these sectors stems from their role as major consumers and providers of energy, which has encouraged the Finnish government to "safeguard" them. As new and nimble players willing to innovate in energy efficiency and distributed energy production emerge, they find it hard to gain equal access to resources and infrastructure.

\subsection{Regulation and policymaking ambiguities}

The ambiguity in regulation and policymaking is a major inhibitor for new investments and broader ecosystem initiatives, as it creates uncertainty regarding the future direction of the energy policy. Though most of our respondents perceived the government's policy targets (e.g., de-carbonizing the energy system by 2050) as rather progressive, they argued that how these targets will be met is still unclear. We found that the slowness of the policymaking environment reinforces these 
ambiguities related to the policy vision and the actual action plan. Our respondents perceived that energy policy always comes a few years behind international development and fails to recognize and promote advanced policies that could grasp the swift technological changes taking place.

The slowness of policymaking is also related to the shortsighted political vision. The transition of political regimes (i.e., the parliament) every four years creates discontinuity in the policy environment and keeps some governments from pushing radical changes and making concrete action plans for the future. This uncertainty hampers any new ecosystem emergence via digitalization or otherwise.

Finally, geopolitical and economic risks can intensify ambiguities in the policymaking environment. The dependency on other countries for energy is not considered a good pre-condition for progressive policymaking, as any attempt to gain energy independence could mean that big energy producers lose their influence and power, and it is uncertain what their reaction would be. Therefore, geopolitical and economic risks can slow progress in the policymaking environment, which can have a negative impact on ecosystem emergence due to uncertainties regarding the future.

\subsection{Cognitive constraints for opportunity recognition}

An important barrier to ecosystem emergence concerns cognitive constraints to opportunity recognition. These constraints involve both new actors trying to form new ecosystems and established actors attempting to make sense of socio-technical change and related opportunities. First, our respondents perceived a great deal of uncertainty over market opportunities, which makes it difficult to identify viable business ventures in the energy sector. In particular, the lack of demand for new services and products and the low electricity prices discourage development and reduce the economic viability of investments.

In addition, the dispersion of necessary capabilities and resources creates further constraints for collectively recognizing and exploiting opportunities. Finnish companies are very small, and they do not have the necessary resources to develop new services and products for final consumers. There are many electricity vendors and distribution companies scattered throughout Finland, resulting in a lack of interconnection among these spatially and thematically dispersed players, making the collective creation of opportunities rather challenging.

Furthermore, regulation that could support the development of and/or give incentives for new business ventures is lacking. "The policy or legislation that could maybe, sometimes, catalyze this kind of services is nonexistent. I am not very positive that the Finnish energy policy would be that innovative in the future, or that it could [support the] creation of new services." The overall lack of policy-driven incentives for innovation intensifies the constraints for opportunity creation and discovery. The following quote vividly describes this situation: "I've been in the industry for long enough to understand that, wherever I put my head, some way or the other, policy will crop up behind the corner. When you look at installing new renewable capacity or managing flexibility... when you have house $A$ and house $B$ wanting to talk to each other, policy forbids it. It is not possible. And here, you would like to see energy resources being shared so that the energy would never leave the neighborhood. It would stay in the neighborhood, and you would not need the huge cable to the neighborhood because the neighborhood could maybe have storage within that community. Now, we're putting in the big cable so that we can produce the energy in a centralized plant, in a volume-efficient way, burning some sort of fuel, at some sort of location." Finally, the tendency of policy decisions to lag behind technological developments inhibits the implementability of new services and, thus, obstructs the innovation and commercialization processes of services providers: "...like, for instance, if we would say to a network, 'We can make sure that you can [get] five years' more life out of your substation with this flexibility management service,' the network will go, 'well, that is all fine, but, in the model, I am only reimbursed for ten years of using the station. Every year after that, it takes out my benefits from my balance sheet because of the regulatory model. If I don't buy a new base station, I'm going to lose money." This is a representative example of policy hindering development and creating major risks for energy companies considering adapting to services.

\subsection{Institutional complexity}

Institutional complexity was perceived as a key hindrance for the renewal of the energy sector. The energy field is rather complicated, with multiple objectives and logics that can be partially conflicting and may lack easy solutions. "When researchers make calculations and models in Excel, they keep adding rows on how the Finnish electricity system should look in 2050, so start from scratch... and yet, there is a long history of existing infrastructure, so you cannot assume us to dismantle the existing infrastructure and start a new one from scratch... So, a mere academic calculation on how the energy system could be 
transformed with unlimited resources, it's a bit too theoretical, and it's not applicable in practice." Thus, the transition to a distributed energy system in which energy is provided and consumed using smart, digital solutions is an extremely difficult, system-level challenge with system-level renewal requirements. For example, there are objectives for climate policy both at the EU level and nationally. The primary means to achieve these goals is through reduced emissions, investments in renewable energy, and energy efficiency. However, these have become separate objectives, which complicates things even further. For example, managing emissions alone does not necessarily provide sufficient incentive to change the energy system.

The complex regulatory environment can slow decision-making and, thus, development. The energy sector is one of the most central industries in Finnish society, which increases the role of authorities. Compared to other industries, authorities highly influence the business environment in the energy sector. The multiple authorities and ministries involved in decision-making also complicates the regulatory environment, creating unnecessary bureaucracy and decelerating investments.

\subsection{Synthesis: Institutional counterforces to innovation ecosystem emergence}

Our analysis suggests the mutual reinforcement of regulation, policymaking ambiguities, the inertia of incumbent actors, and cognitive constraints for opportunity recognition inhibit innovation ecosystem emergence. In addition, institutional complexity functions as an overarching barrier that further sustains the rigidity of incumbent actors and policymakers and creates additional cognitive constraints for opportunity recognition.

As described in Error! Reference source not found., incumbent actors' unwillingness to change due to their path-dependent histories (i.e., "incumbent actor inertia") feeds into and reinforces the cognitive constraints for opportunity recognition. Specifically, taken-for-granted assumptions, the legitimacy of current business logics [25], [41], and the stabilizing influence of shared norms [36] make it difficult for incumbent actors to identify opportunities for new business. "We have such a strong tradition in that area, so if you build a pulp mill and you can sell the pulp for the global markets, then you are in a position where this energy comes from almost nothing invested. So, it's not expensive at all in Finland." On the other hand, cognitive constraints for opportunity recognition can also reinforce incumbent firms' inability to overcome organizational inertia. For instance, due to market uncertainties related to the low electricity prices and a lack of demand, energy companies do not see the opportunity to develop products and services for customers to support, for example, energy efficiency or demand response. Thus, as there is little motivation to change, the inertia of energy companies increases; they do not respond to the changing environment, but instead continue with previously learned practices (see also [21], [16], [42]).

The ambiguities in the policy environment create further cognitive constraints for opportunity recognition. First, the discontinuity between political regimes makes it difficult for energy companies to know which investments are wise and sustainable. In addition, the absence of explicit intentions and decisions concerning concrete measures, as perceived by many of our respondents, does not send the necessary policy signals about where the best opportunities lie. Finally, the traditional view in the energy sector that energy production must occur on a large scale has led to policies focusing on very large centralized energy production. These policies have failed to promote distributed, renewable energy generation, which is where new energy sector ecosystems are emerging. However, renewables have gradually gained a very large market share and do not require large centralized units. Therefore, as policy ambiguities based on the current policy environment increase, it is unclear how actors in the energy sector should make use of common investments in networks or what the nature of the services should be.

Prior literature has highlighted the central role of the wider environment in fostering the acceptance of innovation and supporting and sustaining changes once they occur [36]. However, according to our findings, the complexity of this wider environment can create an additional systemic barrier that actually sustains the full range of cognitive, normative, and regulative constraining forces. First, with respect to incumbent actor inertia and the cognitive constraints on opportunity recognition, many of the actors in the energy sector lack an overall vision or understanding of what is required for a system-level transition. Therefore, as "this kind of big picture, it is missing," incumbent actors become unable to overcome their organizational inertia and drive change in the existing field. For smaller actors with less bargaining power, the field's complexity makes it challenging to recognize and tap into opportunities because "it takes quite a lot of more complex business models and networks." Second, the complexity of the overall energy field also reinforces the ambiguities in policymaking. In particular, as described in the previous sections, policymakers must consider multiple 
objectives and sometimes conflicting factors in their decision-making. Hence, there is no "quick fix where you put out some easy solution," especially when "as regulators, we will still have to be equal and transparent and not discriminate rules in the future for these guys who might not be able to participate in the market."

\section{Discussion and conclusions}

Our study has examined ecosystem emergence barriers in the energy sector. As summarized in Figure 1, we found four system-level barriers: incumbent actor inertia, regulation and policymaking ambiguities, cognitive constraints for opportunity recognition, and institutional complexity. These interlinked barriers sustain the existing status quo and prevent emerging and established actors from creating new ecosystems in the field. A better understanding of these barriers would enable focal actors driving new ecosystem initiatives to identify potential system-level hindrances and find solutions that potentially overcome some of these barriers. The study also informs policymakers on the difficulties in generating new ecosystems in an established and institutionalized field. The study contributes to several literature streams, which we discuss below. Practical and policy implications, as well as limitations and future research directions, are then discussed.

\subsection{Theoretical contributions}

First, our study contributes to the little-researched avenue of ecosystem emergence and the preemergence phase of ecosystems. As discussed by [45], scholars tend to take the existence of an ecosystem for granted, meaning that not enough attention has been paid to the earlier stages of an ecosystem (i.e., its emergence). While some studies have discussed how individual actors can deliberately build innovation ecosystems (e.g., [33], [47], [31]), our study shows that the "natural" emergence of broader innovation ecosystems involves a much more multifaceted set of issues. Thus, it is important to critically examine the broader institutional environment and particular organizational fields (e.g., the energy sector) when analyzing how the grassroots emergence of innovation ecosystems is constrained. Our empirical findings identify several institutional counterforces that together act as system-level barriers. Such understanding is crucial for ecosystem scholars, as it provides a more holistic outlook than the classic entry barriers literature. Furthermore, while our findings mostly relate to the emergence barriers of innovation ecosystems, they might also support a deeper understanding of the barriers to broader ecosystem renewal and transformation, though this is a question for further research to elaborate.

Second, our study contributes to the research on institutional barriers to new technology (e.g., [18] [19], [20], [13], [25]), focusing particularly on the field level [14], [48]. Our study shows that organizational fields involve a variety of field-sustaining mechanisms that mutually reinforce one another over time. Interestingly, our findings on "regulation and policymaking ambiguity," "incumbent actor inertia," and "cognitive constraints for opportunity recognition" are closely linked to the respective dimensions of regulative, normative, and cognitive legitimacy that are used in institutional theory to explain the emergence of new technology. Therefore, different dimensions of legitimacy seem to be an important pre-condition for ecosystem emergence. However, our findings complement these existing perspectives in the institutional literature by providing a more overarching view of the dynamic and interlinked barriers to ecosystem emergence (see Figure 1). These findings contribute to the calls for more research to understand field changes and related restraining forces (cf. [49]). Thus, our study informs the stream of research on how field change is inhibited by incumbents and "institutional elites" with the power to manage and constrain change.

\subsection{Practical and policy implications}

Our results provide practical insights for actors seeking to understand field-level change and "systemlevel" innovations. Our study first reveals the systemic interdependence and consequent inertia hampering the adoption of digitalization and the exploration of business models. The heavy and very long investment cycles of traditional energy sources make interdependent key actors hesitant to pursue any disruptive forces. Compared to other traditional industries, it is more likely that the new digital business models would come from outside rather than inside the traditional industry. Yet, due to the energy industry's systemic nature, and without the support of incumbent players, the emergence of innovation ecosystems is difficult, if not impossible. However, the incumbent players lack the capabilities and the mindset required to build customer-driven digital services. This is a vicious circle that is further hampered by the lack of active policies and regulation supporting industry renewal.

With the advent of new technologies, we expect similar challenges to apply across different industries. Indeed, most major innovations require changing 
and/or challenging existing institutions (regulative, normative, cognitive); therefore, we expect that our results will also apply to other contexts. With respect to the energy sector, it seems that the movement toward digitalization and related renewal is only possible if influential individuals and key stakeholders can join forces for collective strategic action. A joint understanding and shared vision of the energy sector transition is needed, as is the ability to influence the policymaking, regulation, and infrastructures required for research, development, and piloting [17]. However, this transition also requires new players. Innovation rarely comes from industry incumbents [9], and this seems to be the prevailing situation in the Finnish energy sector.

\subsection{Limitations and future research directions}

This study has context-specific and generalizability-related limitations inherent to any exploratory qualitative study, including sector and country specificity. Our findings concerning barriers might be most applicable to other investment-intensive industries with strong state regulation. However, we expect that the results provide a useful overview of the institutional complexities and field-sustaining mechanisms that inhibit ecosystem emergence.

Based on the findings, and acknowledging the limitations, our study provides several avenues for future research. Researchers could focus on different types of processes through which emergence barriers are dissolved, such as institutional work, cooperative interactions between incumbents and entrants [2], and relevant market mechanisms [13]. For instance, it would be interesting to study how individual actors (private or public) can help address and resolve ecosystem emergence barriers by reducing uncertainty, generating collective vision, and creating various types of incentives to join a new ecosystem [see also 6]. In this regard, research integrating social movements, organization theory [15] and institutional entrepreneurship could be potentially useful lenses for examining the emergence of new ecosystems [11]. Finally, it would be interesting to examine institutional complexity (a major barrier to emergence) in more depth. For instance, some institutional scholars have suggested that institutional complexity is also a facilitator of new initiatives [39], [37]. This double role of complexity as both a barrier and an enabler is a fascinating direction for future research in innovation ecosystem emergence.

\section{References}

[1] L. Aarikka-Stenroos and P. Ritala, "Network management in the era of ecosystems: Systematic review and management framework," Industrial Marketing Management, vol. 67, pp. 23-36, 2017.

[2] R. Adner and R. Kapoor, "Value creation in innovation ecosystems: How the structure of technological interdependence affects firm performance in new technology generations," Strategic Management Journal, vol. 31, pp. 306-33, 2010.

[3] R. Adner and R. Kapoor, "Innovation ecosystems and the pace of substitution: Re-examining technology S-curves," Strategic Management Journal, vol. 37, pp. 625-48, 2016.

[4] H. E. Aldrich and C. M. Fiol, "Fools rush in? The institutional context of industry creation," Academy of Management Review, vol. 19, no. 4, pp. 645-70, 1994.

[5] S. S. Ansari, R. Garud, and A. Kumaraswamy, "The disruptor's dilemma: TiVo and the US television ecosystem," Strategic Management Journal, vol. 37, pp. 1829-53, 2016.

[6] E. Autio and L. Thomas, "Tilting the playing field: Towards an endogenous strategic action theory of ecosystem creation," in Open Innovation, Innovation Ecosystems, and Entrepreneurship: Multidisciplinary Perspectives, S. Nambisan, Ed. New Jersey: World Scientific Publishing, 2016.

[7] E. Autio and L. Thomas, "Innovation ecosystems: Implications for innovation management," in The Oxford Handbook of Innovation Management, M. Dodgson, N. Philips, \& D. M. Gann, Eds. Oxford: Oxford University Press, 2016, pp. 204-28.

[8] K. Charmaz, Constructing Grounded Theory. London: SAGE Publications Ltd., 2014.

[9] C. Christensen, The Innovator's Dilemma. Cambridge, MA: Harvard Business School Press, 1997.

[10] B. Clarysse, M. Wright, J. Bruneel, and A. Mahajan, "Creating value in ecosystems: Crossing the chasm between knowledge and business ecosystems," Research Policy, vol. 43, pp. 1164-76, 2014.

[11] M. T. Dacin, J. Goldstein, and W. R. Scott, "Institutional theory and institutional change: Introduction to the special forum," Academy of Management Journal, vol. 45, pp. 4557, 2002.

[12] B. Dattée, O. Alexy, and E. Autio, "Maneuvering in poor visibility: How firms play the ecosystem game when uncertainty is high," Academy of Management Journal, vol. 61, no. 2, pp. 466-98, 2018.

[13] M. Dijk, P. Wells, and R. Kemp, "Will the momentum of the electric car last? Testing an hypothesis on disruptive innovation," Technological Forecasting and Social Change, vol. 105, pp. 77-88, April 2016.

[14] P. J. DiMaggio and W. W. Powell, "The iron cage revisited: Institutional isomorphism and collective rationality in organizational fields," American Sociological Review, vol. 48, pp. $147-60,1983$.

[15] A. Dubois and L. E. Gadde, "Systematic combining: An abductive approach to case research," Journal of Business Research, vol. 55, no. 7, 2002, pp. 553-60.

[16] J. Dutton and S. Jackson, "Categorizing strategic issues: Links to organizational action," Academy of Management Review, vol. 12, pp. 76-90, 1987. 
[17] N. Fliegstein and D. McAdam, "Toward a general theory of strategic action fields," Sociological Theory, vol. 29, pp. 1-26, 2011.

[18] F. W. Geels, “Technological transitions as evolutionary reconfiguration processes: A multi-level perspective and a case-study," Research Policy, vol. 31, pp. 1257-74, 2002.

[19] F. W. Geels, "From sectoral systems of innovation to socio-technical systems: Insights about dynamics and change from sociology and institutional theory," Research Policy, vol. 33, pp. 897-920, 2004.

[20] F. W. Geels and J. Schot, "Typology of sociotechnical transition pathways," Research Policy, vol. 36, pp. 399-417, 2007.

[21] C. G. Gilbert, "Unbundling the structure of inertia: resource versus routine rigidity," Academy of Management Journal, vol. 48, no. 5, pp. 741-63, 2005.

[22] B. G. Glaser and A. L Strauss, Discovery of Grounded Theory: Strategies for Qualitative Research. Chicago: Aldine, 1967.

[23] B. R. Golden, "Research notes. The past is the past-Or is it? The use of retrospective accounts as indicators of past strategy," Academy of Management Journal, vol. 35, no. 4, pp. 848-60, 1992.

[24] R. Gustafsson, M. Jääskeläinen, M. Maula, and J. Uotila, "Emergence of industries: A review and future directions," International Journal of Management Reviews, vol. 18, pp. 28-50, 2016.

[25] J. Markard, S. Wirth, and B. Truffer, "Institutional dynamics and technology legitimacy - A framework and a case study on biogas technology," Research Policy, vol. 45, pp. 330-44, 2016.

[26] J. F. Moore, "Predators and prey: A new ecology of competition," Harvard Business Review, vol. 71, no. 3, pp. 75-86, 1993.

[27] D. S. Oh, F. Phillips, S. Park, and E. Lee, "Innovation ecosystems: A critical examination," Technovation, vol. 54, pp. 1-6, 2016.

[28] M. Parlett and D. Hamilton, "Evaluation as illumination: A new approach to the study of innovatory programs," Edinburgh: Centre for Research in the Educational Sciences, University of Edinburgh, 1972.

[29] A. Pellinen, P. Ritala, K. Järvi, and L. M. Sainio, "Taking initiative in market creation-A business ecosystem actor perspective," International Journal of Business Environment, vol. 5, no. 2, pp. 140-58, 2012.

[30] M. E. Porter, Competitive Advantage: Creating and Sustaining Superior Performance, New York: Free Press, 1985.

[31] P. Ritala, V. Agouridas, D. Assimakopoulos, and O. Gies, "Value creation and capture mechanisms in innovation ecosystems: A comparative case study," International Journal of Technology Management, vol. 63, pp. 244-67, 2013.

[32] P. Ritala and A. Almpanopoulou, 'In defense of 'eco' in innovation ecosystem," Technovation, vol. 60, pp. 39-42, 2017.

[33] R. Rohrbeck, K. Hölzle, and G. H. Gemünden, "Opening up for competitive advantage-How Deutsche Telekom creates an open innovation ecosystem," $R \& D$ Management, vol. 39, pp. 420-30, 2009.
[34] C. G. Sandström, "The non-disruptive emergence of an ecosystem for 3D printing-Insights from the hearing aid industry's transition 1989-2008," Technological Forecasting and Social Change, vol. 102, pp. 160-8, 2016.

[35] G. Schreyögg and J. Sydow, "Organizational path dependence: A process view," Organization Studies, vol. 32, no. 3, pp. 321-35, 2011.

[36] W. R. Scott, Institutions and organizations, 4th ed. Thousand Oaks, CA: Sage, 2014.

[37] J. Siltaloppi, K. Koskela-Huotari, and S. L. Vargo, "Institutional complexity as a driver for innovation in service ecosystems," Service Science, vol. 8, no. 3, pp. 333-43, 2016. [38] R. R. Sinkovics and E. A. Alfoldi, "Progressive focusing and trustworthiness in qualitative research-The enabling role of computer-assisted qualitative data analysis software (CAQDAS)," Management International Review, vol. 52, pp. 817-45, 2012.

[39] M. Smets and P. Jarzabkowski, "Reconstructing institutional complexity in practice: A relational model of institutional work and complexity," Human Relations, vol. 66, no. 10, pp. 1279-1309, 2013.

[40] M. Y. Smith and R. Stacey, "Governance and cooperative networks: An adaptive systems perspective," Technological Forecasting and Social Change, vol. 54, no. 1, pp. 79-94, 1997.

[41] R. Suddaby, A. Bitektine, and P. Haack, "Legitimacy," Academy of Management Annals, vol. 11, pp. 451-78, 2017.

[42] B. M. Staw, L. Sandelands, and J. Dutton, "Threat rigidity effects in organizational behavior," Administrative Science Quarterly, vol. 26, pp. 501-24, 1981.

[43] L. D. Thomas and E. Autio, "The fifth facet: The ecosystem as an organizational field," Academy of Management Proceedings, p. 10306, 2014.

[44] M. Tsujimoto, Y. Kajikawa, J. Tomita, and Y. Matsumoto, "A review of the ecosystem concept-Towards coherent ecosystem design," Technological Forecasting and Social Change, 2017. [Online]. Available doi: 10.1016/j.techfore.2017.06.032

[45] K. Valkokari, "Business, innovation, and knowledge ecosystems: How they differ and how to survive and thrive within them," Technology Innovation Management Review, vol. 5, pp. 17-24, 2015.

[46] S. L. Vargo, H. Wieland, and M. A. Akaka, "Innovation through institutionalization: A service ecosystems perspective," Industrial Marketing Management, vol. 44, 63$72,2015$.

[47] P. J. Williamson and A. De Meyer, "Ecosystem advantage," California Management Review, vol. 55, pp. 2446, 2012.

[48] M. Wooten and A. J. Hoffman, "Organizational fields: Past, present and future," in The Sage Handbook of Organisational Institutionalism, R. Greenwood, C. Oliver, K. Sahlin, and R. Suddaby, Eds. London: Sage, 2008, p. 130147.

[49] C. Zietsma, P. Groenewegen, D. M. Logue, and C. B. Hinings, "Field or fields? Building the scaffolding for cumulation of research on institutional fields," Academy of Management Annals, vol. 11, pp. 391-450, 2017. 